\title{
Schistosoma mansoni-Related Hepatosplenic Morbidity in Adult Population on Kome Island, Sengerema District, Tanzania
}

\author{
Godfrey M. Kaatano', Duk-Young Min², Julius E. Siza', Tai-Soon Yong ${ }^{3, *}$, Jong-Yil Chai ${ }^{4}$, Yunsuk Ko ${ }^{5}$, \\ Su-Young Chang ${ }^{5}$, John M. Changalucha' ${ }^{1}$, Keeseon S. Eom ${ }^{6}$, Han-Jong Rim ${ }^{7}$ \\ 'National Institute for Medical Research, P.O. Box 1462, Mwanza, Tanzania; '2Department of Immunology and Microbiology, Eulji University School of \\ Medicine, Daejeon 34824, Korea; ' ${ }^{3}$ Department of Environmental Medical Biology, Institute of Tropical Medicine and Arthropods of Medical \\ Importance Resource Bank, Yonsei University College of Medicine, Seoul 03722, Korea; ${ }^{4}$ Department of Parasitology and Tropical Medicine, Seoul \\ National University College of Medicine, Seoul 03080, Korea; ${ }^{5}$ Good Neighbors International, Tanzania Western Chapter, P.O. Box 367, Mwanza, \\ Tanzania; ${ }^{6}$ Department of Parasitology, Medical Research Institute and Parasite Resource Bank, Chungbuk National University School of Medicine, \\ Cheongju 28644, Korea; ' Department of Parasitology, College of Medicine, Korea University, Seoul 02841, Korea
}

\begin{abstract}
Schistosomiasis is one of the important neglected tropical diseases (NTDs) in Tanzania, particularly in Lake Victoria zone. This baseline survey was a part of the main study of integrated control of schistosomiasis and soil-transmitted helminths (STHs) aimed at describing morbidity patterns due to intestinal schistosomiasis among adults living on Kome Island, Sengerema District, Tanzania. Total 388 adults from Kome Islands (about 50 people from each village) aged between 12 and 85 years, were examined by abdominal ultrasound according to the Niamey protocol. Liver image patterns (LIPS) A and B were considered normal, and C-F as distinct periportal fibrosis (PPF). The overall prevalence of PPF was $42.2 \%$; much higher in males than in females (47.0\% in male vs $34.4 \%$ in females, $P=0.007$ ). Abnormal increase of segmental branch wall thickness (SBWT) and dilated portal vein diameter (PVD) were also more common in males than in females. Hepatosplenomegaly was frequently encountered; $68.1 \%$ had left liver lobe hepatomegaly and $55.2 \%$ had splenomegaly. Schistosoma mansoni-related morbidity is quite high among adults in this community justifying the implementation of integrated control strategies through mass drug administration, improved water supply (pumped wells), and health education that had already started in the study area.
\end{abstract}

Key words: Schistosoma mansoni, hepatosplenomegaly, adult, Kome Island (Tanzania)

\section{INTRODUCTION}

Approximately 779 million people are at great risk (85\% in Africa) in 78 countries of which 42 are in Africa, and 207 million (97\% in sub-Saharan Africa) are estimated to be affected by schistosomiasis [1]. Out of estimated 201.5 million people infected in sub-Saharan Africa (both Schistosoma mansoni and Schistosoma haematobium) [1], more than a half experience substantial morbidity [2]. It was estimated that about 54 millions are infected with S. mansoni in sub-Saharan Africa, and about 0.93 millions are with hematemesis, likely having severe hepatosplenic morbidity due to intestinal schistosomiasis [2].

- Received 23 July 2015, revised 30 September 2015, accepted 30 September 2015. *Corresponding author (tsyong212@yuhs.ac)

(c) 2015, Korean Society for Parasitology and Tropical Medicine

This is an Open Access article distributed under the terms of the Creative Commons Attribution Non-Commercial License (http://creativecommons.org/licenses/by-nc/3.0) which permits unrestricted non-commercial use, distribution, and reproduction in any

medium, provided the original work is properly cited.
This corresponds with the annual incidence of 180,000 with hematemesis, of whom $83.3 \%$ die annually and also with liver failure being responsible for extra-substantial proportion of death.

Morbidity in intestinal schistosomiasis related to S. mansoni involves the intestinal tract, manifesting with diarrhea, abdominal pain, and blood in the stools. Also infection with $S$. mansoni may present as hepatosplenic schistosomiasis, characterized by enlargement of the liver and spleen and accompanied by increased firmness of the organs [3]. Many of the eggs (about a half) excreted by $S$. mansoni enter the systemic circulation via the portal vein and lodge in the liver [4], where they give rise to vascular and inflammatory granulomatous changes that can lead to periportal fibrosis, portal hypertension with development of esophageal varices, and the risk of life-threatening hematemesis.

Tanzania is among the 7 countries (Burkina Faso, Mali, Sierra Leon, Ghana, Mozambique, Tanzania, and Madagascar) 
most severely affected with schistosomiasis, classified as high prevalence setting [5]. Intestinal schistosomiasis, due to $S$. mansoni, is a serious public health problem which is endemic in many parts of Tanzania [6]. About 19\% of the population in Tanzania is constantly exposed to $S$. mansoni infection especially in rural and peri-urban areas [7]. In Tanzania, extensive transmission of $S$. mansoni occurs along the shores of the Great Lakes [6] and areas of Lake Victoria basin including the lake shores and its associated islands are the most affected areas in Tanzania. For instance among adults from randomly selected villages in Ukerewe islands, Kardoff et al. [8] and Malenganisho et al. [9] found a prevalence of $86 \%$ in Galu and Muriti villages and $78 \%$ in Musozi village, respectively. Of those examined adults, about $41.5 \%$ in Musozi village and $30.0 \%$ in Miriti and Galu villages had periportal fibrosis $[8,9]$. There is also evidence that the level of $S$. mansoni transmission is increasing also in the northeastern and western parts of Lake Victoria shore that previously was regarded as low level or free of transmission areas [10].

Although it is quite clear that, in S. mansoni endemic areas, children and young adolescents exhibit the highest prevalence and intensity of infection [11]; however, severe late-stage consequences are likely during the adulthood, despite generally lower intensities of infection. In order to determine the $S$. mansoni-related hepatosplenic morbidity, the present study targeted on the adult community for collecting morbidity baseline data as mass drug administration (MDA) and other interventions in this control programme targeting all community members of 4 year and above.

\section{MATERIALS AND METHODS}

\section{Study area and population}

Kome Island is a 5th largest island (after Ukerewe, Rubondo, Ukara, and Mwaisome) out of 48\% portion of Lake Victoria surface controlled by Tanzania. The island is in Sengerema District and is situated at longitudinal 32024" and 32024 east and latitude 2014' and 2025. According to the 2002 National census, Kome Island had a population of 38,062 with an average growth rate of $2.9 \%$. Administratively, it has 2 wards, 9 villages and 53 sub-villages. It is served by 1 health centre and 2 dispensaries. It has 10 primary schools and 2 secondary schools in each ward, with almost each village having a primary school, with an exception of Lugata village which has 3 primary schools.
The sources of water for drinking, washing, and other chores are Lake Victoria, natural wells, and streams. The lake harbours the snail intermediate hosts for schistosomes mainly Biomphalaria choanomphala and Biomphalaria sudanica [6,12]. Occupationally most of the people are engaged in peasant farming and fishing activities. They grow cassava, maize, and sweet potatoes as food crops and cotton as a cash crop. Livestock include cattle, goats, chickens, ducks, and a few pigs. All the occupational as well as recreational activities have obvious bearing to acquisition and transmission of intestinal schistosomiasis, soil-transmitted helminths (STHs), and other parasitic diseases like malaria and amebiasis in the study area.

\section{Study design and sampling procedure}

A cross sectional study was conducted on Kome Island in February 2009 to obtain baseline data on S. mansoni infection status and S. mansoni-related hepatosplenic morbidity using ultrasonography before implementation of intervention. Before the survey, meetings were held in each village and the purpose of the study was explained. About 50 adult participants in each 8 villages (all villages in Kome Island) were randomly selected and recruited to participate in this study. A subsample of older (12 years and above) schoolchildren (13 in Lugata Secondary School and 20 in Kabaganga Primary School) were also recruited.

\section{Data collection, materials and methods}

Participants were given a container to collect stool specimens. The cllected stools were processed by the Kato-Katz technique using a $42.7 \mathrm{mg}$ template, and microscopic examination of the prepared Kato's slides for S. mansoni eggs was carried out in the field. The mean intensity of $S$. mansoni eggs was determined by taking the average number of eggs in each slide and then multiplying by 24 to obtain the number of eggs per gram (epg) of feces, which is referred as the intensity of infection.

Ultrasound examination was performed using a portable ultrasound, according to standard guidelines proposed by Niamey working group [13]. A portable ultrasound scanner equipped with a $3.5 \mathrm{MHz}$ curved array transducer was used. The size of the liver (left and right lobes) and spleen was measured and their height adjusted according to the reference population. The portal hypertension (PH) score was calculated by combining the measurement of the diameter of the lumen of the portal vein (PV) and screening for the presence of ascites 
(ascites score) and porto-systemic collateral vessels (collateral score). For comparison of age independent analysis of organometric data, we used established height-related reference data of Senegalese African community for the values of liver, spleen, and main portal vein [14].

Both methods, qualitative using pattern image and quantitative by measuring segmental branch wall thickening (PBWT), were used in assessing periportal fibrosis. The liver image pattern (LIP) was assessed as pattern A, B, C, D, E, and F according to the guidelines [13]. Periportal thickening seen by ultrasonography as echo dense areas was measured at the level of the first segmental branches leaving the left branches of the main portal vein at the point where the most substantial wall thickness was observed. Segmental branch wall thickness (SBWT) was obtained by measuring external (outer to outer) diameter followed by measurement of lumen (inner to inner) diameter. The difference between the 2 measurements was recorded as PBWT. The gall bladder wall thickness was measured when the gall bladder was well visualized. The thickness of the gall bladder was categorized as normal when it was less than 4 $\mathrm{mm}$, or increased when greater or equal to $4 \mathrm{~mm}$ in diameter.

\section{Data handling and analysis}

Ultrasonographic organomegaly was defined as the left liver lobe, right liver lobe, or spleen length exceeding 2SD above the normal reference value, whereas right liver lobe shrinkage was defined as exceeding negative 2SD below normal reference value. The main portal vein and PBWT dilatation were also considered present if exceeding 2SD above the normal reference value. Patterns A and B were considered to show no PPF while C, D, E, and F were recorded as PPF. The cases with pattern B and PBWT exceeding 2SD were considered as PPF.

Data entry was done using Dbase IV (Borland International, Scotts Valley, California, USA) and a double entry system was used for quality control. Data was transferred to STATA version 8 software (Stata Corp 2000, College Station, Texas, USA) for analysis. Analysis was done by generation of some frequency tables, cross tabulations, and calculation of the prevalence. To compare the mean intensity of infection by sex, age groups, and village, $t$-test was used. Means were regarded as significant if $t<0.05$. For comparing PPF and infection prevalence (proportion) by respective groups as above, the chi-square test was used and a proportion was considered as significant if $P<0.05$.

\section{RESULTS}

A total of 388 participants were recruited for ultrasonography and parasitological examinations. Due to a logistical

Table 1. Prevalence of periportal fibrosis (PPF) and segmental branch wall thickening (PBWT), portal pressure, and S. mansoni infection intensity and prevalence by age, sex, and village in Kome island, Sengerema, Tanzania

\begin{tabular}{|c|c|c|c|c|c|c|c|c|c|c|c|}
\hline \multirow{3}{*}{$\begin{array}{l}\text { Age group } \\
\text { (year) }\end{array}$} & \multirow{3}{*}{$\begin{array}{l}\text { No. } \\
\text { exam. }\end{array}$} & \multirow{2}{*}{\multicolumn{3}{|c|}{ Periportal fibrosis (PPF) }} & \multicolumn{7}{|c|}{ S. mansoni infection status } \\
\hline & & & & & \multicolumn{4}{|c|}{ Prevalence } & \multicolumn{3}{|c|}{ Intensity of infection } \\
\hline & & Total & Male & Female & No. exam. & Total & Male & Female & All & Male & Female \\
\hline $10-19$ & 29 & $11(37.9)$ & $7(46.7)$ & 4 (28.6) & 30 & 19 (63.3) & $11(65.8)$ & $8(57.1)$ & 65.7 & 11 (65.8) & 8 (57.1) \\
\hline $20-29$ & 67 & $28(41.8)$ & $17(51.5)$ & $11(32.4)$ & 70 & 27(38.6) & $17(50.0)$ & $10(27.9)$ & 88.0 & $17 \quad(50.0)$ & $10(27.9)$ \\
\hline $30-39$ & 96 & $47(49.0)$ & $31(56.4)$ & $16(39.0)$ & 107 & $8(26.2)$ & $16(28.1)$ & $12(24.0)$ & 97.7 & 16 (28.1) & $12(24.0)$ \\
\hline $40-49$ & 79 & $31(39.2)$ & $21(45.7)$ & $10(30.0)$ & 83 & $24(28.9)$ & $14(29.8)$ & $10(27.8)$ & 118.0 & 14 (29.8) & $10(27.8)$ \\
\hline $50-60$ & 52 & $24(46.2)$ & $15(48.4)$ & 9 (42.9) & 56 & $14(25.0)$ & $10(30.3)$ & $4(17.4)$ & 156.0 & $10(30.3)$ & $4(17.4)$ \\
\hline 60 and over & 37 & $11(29.7)$ & $6(30.0)$ & $5(29.4)$ & 42 & 9 (21.4) & 7 (29.2) & $2(11.2)$ & 128.0 & 7 (29.2) & 2 (11.2) \\
\hline Total & 360 & $152(42.2)$ & $97(48.5)$ & 55 (34.4) & 388 & $121(31.2)$ & 75 (35.5) & $46(26.0)$ & & 75 (35.5) & 46 (26.0) \\
\hline \multicolumn{12}{|l|}{ Village name } \\
\hline Nyamiswi & 28 & $13(46.4)$ & $8(47.1)$ & $5(45.5)$ & 37 & $4(10.8)$ & $2(10.5)$ & $2(11.1)$ & 42.0 & $2(48)$ & 2 (36) \\
\hline Bugoro & 45 & 22 (48.9) & $15(50.0)$ & $7(46.7)$ & 50 & 7 (14.0) & 7 (21.2) & $\begin{array}{ll}0 & (0.0)\end{array}$ & 76.4 & 7 (75.4) & $\begin{array}{ll}0 & (0.0)\end{array}$ \\
\hline Lugata & 56 & 19 (33.9) & $13(36.1)$ & $6(30.0)$ & 58 & $14(24.1)$ & $10(27.0)$ & $4(19.1)$ & 56.6 & 10 (62.4) & 4 (42) \\
\hline Buhama & 40 & $12(30.0)$ & $6(30.0)$ & $6(30.0)$ & 46 & 13 (28.3) & $6(30.0)$ & 7 (26.9) & 112.6 & 6 (104) & 7 (120) \\
\hline Kabaganga & 54 & 21 (38.9) & $11(42.3)$ & $10(35.7)$ & 57 & 22 (38.6) & $12(41.4)$ & $10(35.7)$ & 63.3 & 12 (78) & 10 (45.6) \\
\hline Isenyi & 39 & 22 (56.4) & $17(77.3)$ & 5 (29.4) & 40 & $14(35.0)$ & 9 (39.1) & 5 (29.4) & 97.7 & 9 (109.3) & 5 (76.8) \\
\hline Nyakasasa & 48 & 19 (39.6) & $16(57.1)$ & $3(15.0)$ & 50 & 21 (42.0) & 14 (48.3) & 7 (33.3) & 126.8 & 14 (102.8) & 7 (74.8) \\
\hline Izindabo & 50 & $24(48.0)$ & $11(52.4)$ & $13(44.8)$ & 50 & $26(52.0)$ & 15 (71.3) & $11(37.9)$ & 159.7 & 13 (216) & 11 (82.9) \\
\hline Total & 360 & $152(42.2)$ & 97 (48.5) & $55(34.4)$ & 388 & $121(31.2)$ & 75 (35.6) & $46(26.0)$ & & & \\
\hline
\end{tabular}


problem, 32 individuals in Buhama village were not measured for the left liver lobe size, right liver lobe size, and main portal vein size, including 5 individuals in Kabaganga village in whom their heights were not taken. These cases were therefore excluded from the analysis of organometric data. Of 388 included, 28 (7.2\%) individuals had other abnormalities and hence were excluded in scoring and assessing PPF using the pattern image.

Of the 360 total individuals examined by ultrasonography, 152 (42.2\%) had evidence of periportal fibrosis (PPF) (by LIP); $30.6 \%$ had mild PPF (pattern B, C, and D) and 10.8\% had severe PPF (pattern E and F). Of 36 with severe PPF, 29 (8.8\%) had pattern E and 7 (2.0\%) had pattern F. Of 152 with PPF, $87.2 \%$ (136/152) of them had evidence of SBWT; thus being confirmed by quantitative method of assessing PPF. The prevalence of PPF was higher in male (47.0\%) than in female (34.4\%; $P=0.007$ ). The prevalence of severe PPF was also remarkably higher in male $(15 \%)$ than in female $(5 \%$; $P=$ 0.001). The prevalence of PPF increases with age and then almost remained constant throughout the adulthood. The prevalence of PPF was consistently high in all 8 villages; Isenyi village leading with $56.4 \%$ prevalence while Buhama village was the lowest with $30.0 \%$. The prevalence of $S$. mansoni was also higher in male $(35.6 \%)$ than in female $(26.0 \% ; P=0.043)$ but the prevalence decreased with increase in age (Table 1).

Fecal egg excretion in positive cases was between 24 and 984 (median 48). There was no difference of median or mean egg excretion by sex (median, male 48 epg vs female 48 epg; mean, male 113.0 epg vs female $88.2 \mathrm{epg}, P=0.3708)$. The quantitative fecal egg excretion (mean epg) was the highest in the older age group (156.0 and 128.0 epg in the 50-59 and 60 and over age groups, respectively), and in Izindabo (159.7 epg) and Nyakasasa (126.8 epg) villages. However, the differences from the rest age groups and villages were not significant by Pearson chi-square or $t$-test.

Hepatosplenomegaly assessed as non-specific findings related to $S$. mansoni infection was also common in Kome Island; $55.2 \%$ had splenomegaly and $68.1 \%$ had left lobe hepatomegaly. The prevalence of the right liver lobe shrinkage was $14.8 \%$, and the right liver lobe enlargement was $6.7 \%$. The shrinkage of the right liver lobe was higher in male (19.0\%) than in female $(9.6 \% ; P=0.014)$ (Table 2).

Of 152 patients with PPF, 24 (15.8\%) had irregular or nodular liver surface, 10 (5.9\%) showed that their liver edge was abnormally round, and 27 (17.1\%) showed distorted or convexed liver shape. The gall bladder wall thickness as an evidence of involvement by periportal fibrosis was present in 67 patients (44.1\%). In all of these 67 cases, gallbladder wall thickening was associated with central portal fibrosis. Collateral vessels were detected in 42 patients (27.6\%) and ascites in 4 patients (2.6\%).

Twenty-eight had other specified pathological abnormalities of the liver not to be related to $S$. mansoni infection; their majority had fatty liver (24.4\%), hemangioma (17.9\%), and gallstone $(10.7 \%)$.

Table 2. Prevalence of organomegaly and portal pressure by sex and village name in Kome Island, Sengerema, Tanzania

\begin{tabular}{|c|c|c|c|c|c|c|c|c|c|}
\hline \multirow{3}{*}{ Category } & \multicolumn{5}{|c|}{ Liver size alteration, no. (\%) } & \multicolumn{2}{|c|}{ Splenomegaly, no. (\%) } & \multicolumn{2}{|c|}{ Portal pressure, no. (\%) } \\
\hline & \multirow{2}{*}{ No. exam. } & \multirow{2}{*}{$\begin{array}{l}\text { Left lobe } \\
\text { enlarged }\end{array}$} & \multicolumn{3}{|c|}{ Right lobe } & \multirow{2}{*}{ No. exam. } & \multirow{2}{*}{ Spleen } & \multirow{2}{*}{ No. exam. } & \multirow{2}{*}{$\mathrm{PHT}$} \\
\hline & & & Enla & arged & Shrinked & & & & \\
\hline \multicolumn{10}{|l|}{ Sex } \\
\hline Male & 195 & $128(65.6)$ & 10 & $(5.1)$ & $37(19.0)$ & 208 & $112(53.9)$ & 200 & $72(36.0)$ \\
\hline Female & 156 & $111(71.2)$ & 14 & $(9.0)$ & $15(9.6)$ & 174 & $99(56.9)$ & 160 & $52(32.5)$ \\
\hline Total & 351 & $239(68.1)$ & 24 & $(6.7)$ & $52(14.8)$ & 382 & $211(55.2)$ & 360 & $124(34.4)$ \\
\hline \multicolumn{10}{|l|}{ Village name } \\
\hline Nyamiswi & 37 & $18(48.7)$ & 3 & $(8.1)$ & $4(10.8)$ & 37 & $17(45.9)$ & 28 & $4(14.3)$ \\
\hline Bugoro & 50 & $43(86.0)$ & 2 & $(4.0)$ & $8(16.0)$ & 50 & $26(52.0)$ & 45 & $16(35.6)$ \\
\hline Lugata & 58 & $37(63.8)$ & 5 & (8.6) & $10(17.2)$ & 58 & 28 (48.3) & 56 & $11(19.6)$ \\
\hline Buhama & 14 & 7 (50.0) & 0 & $(0.0)$ & $3(21.4)$ & 45 & $26(57.8)$ & 40 & $34(85.0)$ \\
\hline Kabaganga & 52 & 33 (63.5) & 3 & (5.8) & $4 \quad(7.7)$ & 52 & 31 (59.6) & 54 & $14(25.9)$ \\
\hline Isenyi & 40 & 28 (70.0) & 3 & (7.5) & $6(15.0)$ & 40 & $31(77.5)$ & 39 & $17(34.6)$ \\
\hline Nyakasasa & 50 & 37 (74.0) & & (10.0) & $9(18.0)$ & 50 & 28 (56.0) & 48 & $12(25.0)$ \\
\hline Izindabo & 50 & $36(72.0)$ & 3 & $(6.0)$ & $8(16.0)$ & 50 & $24(48.0)$ & 50 & 16 (32.0) \\
\hline Total & 351 & $239(68.1)$ & 24 & (6.8) & $52(14.8)$ & 382 & $211(55.2)$ & 360 & $124(34.4)$ \\
\hline
\end{tabular}




\section{DISCUSSION}

The baseline finding clearly shows that there is high prevalence of PPF (42.2\%) and other S. mansoni-related hepatosplenic morbidity in the communities of Kome Island. The left lobe hepatomegaly that was found in $68.1 \%$, the right liver lobe shrinkage in $14.8 \%$, and splenomegaly in $55.2 \%$ indicated a high morbidity in Kome community caused by S. mansoni infection. The prevalence of PPF in this community was similar to $41.5 \%$ observed by Malenganisho et al. [9] in Musozi village which is believed to be most highly affected with intestinal schistosomiasis in Ukerewe District. However, our figure was comparatively higher than $30.0 \%$ and $24.4 \%$ in a study done in the same areas of Ukerewe Islands among randomly selected adult community members as were observed by Kardoff et al. [8] and Kaatano et al. [15], respectively. The morbidity related to $S$. mansoni was also much higher in the villages on proximity with the lake shore, agreeing to a similar observation by Kaatano and others in 1993 (unpublished observations) in Ukerewe (PPF $30.7 \%$ in onshore vs $18.7 \%$ in inland villages) as was expected. S. mansoni normally is highly prevalent along the lake shore [16]. Since living on or near the lakeshore is ecological proxy for risky water-contact behavior because those individuals in these areas are more likely to undertake risky water-contact behavior in comparison with the ones who are distant from the lake.

However, on the other hand, the prevalence of PPF of $42.2 \%$ as observed in our study area was comparatively higher than other studies in the rest other East Africa along Lake Victoria shore using the Niamey protocol. King et al. [17] in Kenya revealed a prevalence of PPF of 3\% while Booth et al. [18] recorded the prevalence of PPF of $31.5 \%$ and $6.1 \%$ in 2 villages of Uganda along the shores of Lake Albert. Geographical variation in levels of morbidity and infection rate is a common phenomenon, in part mainly being attributed in part to the focal nature of transmission [19], which has been observed in even very close in adjacent communities [20].

The finding of the prevalence of PPF being significantly higher in male than female is as expected as and was also confirmed by other workers $[8,9]$. Water contact activities such as swimming and fishing which are normally commoner for males than females; in most cases of the male water contact (swimming, fishing, etc) takes long and usually involves most part of the body in contact with lake water. However, one of the important and striking observations in this study was the occurrence of the high prevalence of PPF (37\%) in the teenage group of 10-20 years. Similar trends of observation were recorded by Malenganisho et al. [9] in Musozi village, Ukerewe Islands District and by Gabone et al. [21] in Kome Island, Sengerema District, Lake Victoria. This result contrasts with that of Vennervald et al. [3] from an endemic area of Kenya where a similar age group did not show significant PPF despite high rates of splenomegaly and hepatomegaly. In another study in Ukerewe [15] which were rather more representative of all community members, its prevalence in same age group was $12.5 \%$ while $5.4 \%$ of PPF was detected by El-Scheich et al. [22] among school age children in Ukerewe. This finding probably supports the ideas that intensive exposure to heavy infection during early childhood in high transmission areas is responsible for such rapid progression of morbidity. Earlier studies [23] estimated the time lapse between infection with $S$. mansoni and evolution of PPF in humans to be at least 5 years. However, the evolution of PPF in our setting of Lake Victoria region as compared with Sudan [23] and other part of northern Africa might be longer where Kardoff et al. [8] classified it as intermediate. Although our study did not include children less than 14 years, it can be inferred that in an established stable transmission area, such as the shores of Lake Victoria, PPF starts to develop in childhood. Such assumption is also supported by PPF (4.7\%) detected in Ukerewe [15] among 5-10 years age group.

Observation of the lower egg excretion detection rate (i.e., low S. mansoni infection prevalence) might be attributed to methodology of collection of stool samples. Due to logistic reason, in our case only 1 stool sample was collected instead of 2 samples in 2 consecutive days that might underestimate the infection rate due to the fact that by examination of a single stool sample, particularly in low intensity, cases are frequently missed as a result of less sensitive when only 1 stool sample is examined [24]. However, the procedures of sample collection and parasitological testing were ensured to be the same throughout the baseline survey. This fact is also supported by relatively higher rate of periportal fibrosis and also by degree of discordance between hepatic fibrosis and demonstration of eggs in stools noted in our study; 65.1\% (99/152) of those individuals with detectable hepatic fibrosis at the baseline survey had no demonstrable eggs in their stools.

Conclusively, a high S. mansoni-related morbidity justifies the implementation of mass drug administration and other intervention such as provision of alternative sources of water 
supply (pumped wells) that has already started in the study area.

\section{CONFLICT OF INTEREST}

We have no conflict of interest related to this work.

\section{REFERENCES}

1. Steinmann P, Keiser J, Bos R, Tanner M, Utzinger J. Schistosomiasis and water resources development: systematic review, metaanalysis, and estimates of people at risk. Lancet Infect Dis 2006; 6: 411-425.

2. van der Werf MJ, de Vlas SJ, Brooker S, Looman CW, Nagelkerke NJ, Habbema JD, Engels D. Quantification of clinical morbidity associated with schistosome infection in sub-Saharan Africa. Acta Trop 2003; 86: 125-139.

3. Vennervald BJ, Kenty L, Butterworth AE, Kariuki CH, Kadzo H, Ireri E, Amaganga C, Kimani G, Mwatha J, Otedo A, Booth M, Ouma JH, Dunne DW. Detailed clinical and ultrasound examination of children and adolescents in a Schistosoma mansoni endemic area in Kenya: hepatosplenic disease in the absence of portal fibrosis. Trop Med Int Health 2004; 9: 461-470.

4. Cheever AW, Andrade ZA. Pathological lesions associated with Schistosoma mansoni infections in man. Trans R Soc Trop Med Hyg 1967; 61: 626-639.

5. Utzinger J, Raso G, Brooker S, De Savigny D, Tanner M, Ørnbjerg N, Singer BH, N'goran EK. Schistosomiasis and neglected tropical diseases: towards integrated and sustainable control and a word of caution. Parasitology 2009; 136: 1859-1874.

6. McCullough FS. The distribution of Schistosoma mansoni and Schistosoma haematobium in East Africa. Trop Geogr Med 1972; 24: 199-207.

7. World Health Organization. Report of the WHO informal consultation on schistosomiasis in low transmission areas: control strategies and criteria for elimination. London, UK. 10-13 April 2000. WHO/CDS/CPE/SIP/SIP2001.1; www.who.int/ctd. 2001.

8. Kardorff R, Gabone RM, Mugashe C, Obinga D, Ramarokoto CE, Mahlert C, Spannbrucker N, Lang A, Gunzler V, Gryseels B, Ehrich JHH, Doehring E. Schistosoma mansoni related morbidity in Ukerewe Island, Tanzania: clinical, ultrasonographical and biochemical parameters. Trop Med Int Health 1997; 2: 230-239.

9. Malenganisho WL, Magnussen P, Friis H, Siza J, Kaatano G, Temu M, Vennervald BJ. Schistosoma mansoni morbidity among adults in two villages along Lake Victoria shore in Mwanza, Tanzania. Trans R Soc Trop Med Hyg 2008; 102: 532-541.

10. Gabone RM, Lwambo JNS. Epidemiology of S. mansoni and geohelminthiasis in Bukoba town, Kagera Region, Tanzania. Quarterly Report of the National Institute for Medical Research, Mwanza Medical Research Centre, Tanzania. 1994, pp. 7-11.

11. Kabatereine NB. Schistosoma mansoni in a fishing community on the shores of Lake Albert at Butiaba, Uganda: epidemiology, morbidity, re-infection patterns and impact of treatment. Ministry of Health Uganda, Faculty of Science, University of Copenhagen and Danish Bilharziasis Laboratory. Copenhagen, Denmark. 2000, pp. 73-75.

12. Magendantz M. The biology of Biomphalaria choanomphala and Biomphalaria sudanica in relation to their role in the transmission of Schistosoma mansoni in Lake Victoria at Mwanza. Bull World Health Organ 1972; 47: 331-342.

13. Richter J, Hatz C, Campagne G, Bergquist NR, Jenkins JM. Ultrasound in Schistosomiasis. A Practical Guide to the Standardized Use of Ultrasonography for the Assessment of Schistosomiasis Related Morbidity. World Health Organization, Geneva, Switzerland. TDR/STR/SCH/00.1. 2000.

14. Yazdanpanah Y, Thomas AK, Kardorff R, Talla I, Sow S, Niang M, Stelma FF, Decam C, Rogerie F, Gryseels B, Capron A, Doehring E. Organometric investigations of the spleen and liver by ultrasound in Schistosoma mansoni endemic and non-endemic villages in Senegal. Am J Trop Med Hyg 1997; 57: 245-249.

15. Kaatano GM. Impact of three years praziquantel treatment and health education on intestinal schistosomiasis infection and related hepatosplenic morbidity in rural island community in Northern-Western, Tanzania. Thesis for MPH, University of Jerusalem, Israel. 2003.

16. Doumenge JP, Mott K, Cheung C, Villenave D, Chapuis O, Perrin $\mathrm{M}$, Reaud-Thomas G. Atlas of the Global Distribution of Schistosomiasis. Bordeaux, France. Universite de Bordeaux. 1987.

17. King CH, Blanton RE, Muchiri EM, Ouma JH, Kariuki HC, Mungai P, Magak P, Kadzo H, Ireri E, Koech DK. Low heritable component of risk for infection intensity and infection-associated disease in urinary schistosomiasis among Wadigo village populations in Coast Province, Kenya. Am J Trop Med Hyg 2004; 70: $57-62$.

18. Booth M, Vennervald BJ, Kabatereine NB. Demographic patterns of organ size and periportal fibrosis vary considerably between neighbouring communities in Uganda heavily exposed to Schistosoma mansoni infection. Trans R Soc Trop Med Hyg 2004; 98: 128-136.

19. Guyatt H, Gryseels B, Smith T, Tanner M. Assessing the public health importance of Schistosoma mansoni in different endemic areas: attributable fraction estimates as an approach. Am J Trop Med Hyg 1994; 53: 660-667.

20. Boisier P, Ramarokoto CE, Ravoniarimbinina P, Rabarijaona L, Ravaoalimalala VE. Geographic differences in hepatosplenic complications of schistosomiasis mansoni and explanatory factors of morbidity. Trop Med Int Health 2001; 9: 699-706.

21. Gabone RM, Mugashe CL, Malenganisho WLM, Asztely A, Senkoro KP, Nilsson LA, Ouchterlony O. Ultrasonic evaluation of hepatosplenic morbidity in population of Kome Island. In Proceedings of the 11th NIMR Annual Joint Scientific Conference with a Seminar on Malaria Control Research, 22-25 February 1993. Arusha, Tanzania. 1993, pp. 171-182. 
22. El Scheich T, Hofer L, G. Kaatano G, Foya J, Odhiambo D, Igogote J, Lwambo N, Ekamp H, Karst K, Häussinger D, Richter J. Hepatosplenic morbidity due to Schistosoma mansoni in schoolchildren on Ukerewe Island, Tanzania. Parasitol Res 2012; 110: 2515-2520.

23. Homeida M, Ahmed S, Dafalla A, Suliman S, ElTom T, Nash T,
Bennet JL. Morbidity associated with Schistosoma mansoni infection as determined by ultrasound: a study in Gezira, Sudan. Am J Trop Med Hyg 1988; 39: 196-201.

24. Engels D, Sinzinkayo E, Gryseels B. Day-to-day egg count fluctuation in Schistosoma mansoni infection and its operational implications. Am J Trop Med Hyg 1996; 54: 319-324. 
